\title{
BENEFÍCIOS FUNCIONAIS DO CACAU (Theobroma cacao) E SEUS DERIVADOS
}

\section{FUNCTIONAL BENEFIT OF COCOA (Theobroma cacao) AND THEIR DERIVATIVES}

\author{
Heloisa de Oliveira RIBAS'; Danyellen Staut GONÇALVES'; Caryna Eurich MAZUR²
}

1 - Graduanda em Nutrição. Universidade Estadual do Centro-Oeste (UNICENTRO).

2 - Nutricionista. Docente da Universidade Estadual do Centro-Oeste (UNICENTRO).

Autor para correspondência: hribas98@hotmail.com

\section{RESUMO:}

O cacau (Theobroma cacao) é um fruto originário da América do Sul e da América Central popular pela sua rica concentração de compostos fenólicos, seu sabor e por ser matéria prima do chocolate. Esta revisão de literatura tem como objetivo apresentar os benefícios provindos do cacau e seus componentes na saúde dos consumidores. Para isso foram reunidos artigos superiores ao ano de 2009. Os resultados comprovaram que o cacau em uma dieta balanceada tem efeito antioxidante, antiaterosclerótico, previne dislipidemias e pode ter influência contra o envelhecimento dérmico. Portanto consumido de forma adequada e em uma dieta balanceada pode trazer benefícios para o sistema cardiovascular, ter influência em dislipidemias e retardar o envelhecimento cutâneo.

Palavras-chave: antioxidante, chocolate, polifenóis.

\section{ABSTRACT:}

Cocoa (Theobroma cacao) is a fruit originating in South America and Central America popular for its rich concentration of phenolic compounds, its flavor and for being the raw material of chocolate. This literature review aims to present the benefits of cocoa and its components in consumer health. The results showed that cocoa in a balanced diet has antioxidant, antiatherosclerotic effect, prevents dyslipidemias and may have influence against dermal aging. Therefore consumed properly and in a balanced diet can bring benefits to the cardiovascular system, influence on dyslipidemias and delay skin aging.

Key words: antioxidant, chocolate, polyphenols.

\section{INTRODUÇÃO}

O cacau (Theobroma cacao) é um fruto originalmente da América do Sul e da América Central disseminado por todo o mundo. A popularidade vem, não só pelas suas propriedades funcionais, mas também pelo seu sabor e, principalmente, por ser a matéria prima do chocolate (MEDEIROS, 2010).

O fruto divide-se em casca, polpa e sementes. As sementes são compostas por um gérmen e dois cotilédones, que apesar de serem envolvidas por uma camada de mucilagem doce, ainda assim tem sabor amargo (NOGUEIRA, 2015).

Há relatos de que o cacau tem propriedades antioxidantes e anti-inflamatórias. 
Atuando também na diminuição do LDL-colesterol e na queda da prevalência e incidência de doenças cardiovasculares. Isso porque contém altos níveis de compostos fenólicos (EFRAIM et al., 2011).

Sabe-se que os compostos fenólicos são um amplo grupo de substâncias provindas do metabolismo de plantas, que podem ser distribuídos de acordo com sua estrutura ou classe. Dentre este grupo estão presentes os flavonoides e procianidinas, os quais são encontrados no cacau. Nos flavonoides estão presentes os flavonóis, flavononas, flavonas e antocianinas. Dentre os flavonóis, estão as catequinas e as epicatequinas, responsáveis pela formação das procianidinas que, quando presentes no organismo humano, exercem efeitos antioxidantes retardando o aparecimento de doenças, além de inibir a formação de infecções agudas e melhorar a saúde cardiovascular (EFRAIM et al., 2011).

Entre essas melhoras no sistema cardiovascular, destaca-se a redução significativa da formação de coágulos. Isso se dá pela menor agregação plaquetária, devido à ação das catequinas presentes no fruto e alimentos fonte (GIGLIO et al., 2018).

Sendo um fruto versátil, o cacau pode ser inserido na alimentação, facilmente, na forma de cacau em pó, polpa de cacau, chocolates com um percentual elevado de cacau, entre outras opções (DUARTE et al., 2016). Esta revisão tem como objetivo apontar os benefícios que a inserção do cacau e seus derivados irão trazer no organismo de potenciais consumidores.

\section{METODOLOGIA}

O presente trabalho é uma revisão integrativa de literatura, utilizando como fonte de dados as bases PubMed, Scielo e Lilacs. Os artigos selecionados foram publicados de 2009 até 2018, tendo critérios de exclusão os com publicação anterior a 2009. As palavraschave inseridas para as buscas dos trabalhos foram: "cocoa, properties", "phenolic", "health", "Theobroma cacao", "polyphenols" e "chocolate".

Os parâmetros para inclusão foram artigos que buscaram explorar as propriedades dos compostos fenólicos presentes no cacau e explanar os benefícios do uso do mesmo e de derivados. Foram inclusos artigos em português, inglês e espanhol, estudos originais com os mais diversos delineamentos e estudos realizados em humanos ou animais.

Após análise do título e do resumo, a amostra deste artigo perfez vinte e quatro artigos que foram lidos na íntegra e extraídos os resultados mais importantes a fim de constar nesta revisão de literatura. Os resultados serão mostrados de maneira descritiva. 


\section{RESULTADOS}

\subsection{Propriedades $x$ consumo}

O cacau é um produto muito versátil, podendo ser consumido nas suas diferentes formas, seja em misturas com outros ingredientes ou até mesmo puro na forma de pó. Para se obter resultados positivos quanto ao seu consumo em chocolates e produtos industrializados, é necessário que o teor de cacau presente seja elevado, pois ao passo que aumenta os níveis do cacau, aumentam-se os compostos fenólicos. Contudo, esse aumento faz com que o produto se torne mais caro para o consumidor (EFRAIM et al., 2011).

Além disso, produtos com grandes concentrações de açúcares e gorduras quando consumidos desenfreadamente se tornam prejudiciais e impulsionam o ganho de peso, como é visto no chocolate ao leite. Isso porque essas substâncias quando consumidas em grande escala são depositadas na forma de gordura corporal. Essa deposição de gordura corporal a longo prazo é o que irá gerar comorbidades, como dislipidemias, diabetes mellittus, hipertensão e outras doenças crônicas não transmissíveis (DCNT) (RIBEIRO; SANTOS, 2013).

Dessa forma, os produtos, à base deste fruto, que passam por menor processamento e que contenham de 50 e $70 \%$ de cacau são os mais recomendados para o consumo diário pois possuem maior quantidade de polifenóis. Sendo que, é através dos polifenóis que virão os benefícios esperados. Entretanto, os compostos do cacau na presença de carboidratos e proteínas se complexam, isso faz com que tenham uma sensação de adstringência e amargor, causando menor aceitação por parte dos apreciadores de produtos com cacau. As sementes do cacau passam por um préprocessamento para eliminar essa sensação, levando então a perda das suas propriedades antioxidantes, anti-inflamatórias e cardioprotetora (EFRAIM et al., 2011).

Genovese et al. (2009) mostrou que quando comparado o teor de compostos fenólicos presentes no pó do cacau e na semente de cupuaçu, observou-se que apesar de o cupuaçu possuir maior aporte de flavonoides que o cacau, ele possui cerca de 3 vezes menos compostos e polifenóis totais que a semente de cacau, sendo então o pó do cacau uma melhor escolha de suplementação para suas atividades antioxidantes. 


\subsection{Efeitos no sistema cardiovascular e pressão arterial}

A partir da análise de vários estudos o consumo de cacau nas suas diversas formas, como o cacau em pó e o chocolate, possui grande influência no sistema cardiovascular através de seus compostos bioativos, os quais têm capacidade de reduzir a pressão arterial (PA) significativamente e amenizar os efeitos de radicais livres (GIGLIO et al., 2018).

Isso porque os compostos bioativos presentes em todo o cacau, desde a casca até a polpa, são potentes antioxidantes. Dessa forma, diminuem o estresse oxidativo nas membranas plasmáticas. Além disso, o cacau é fonte de magnésio e potássio tendo um efeito cardioprotetor (GIGLIO et al., 2018).

Um estudo experimental feito em ratos alimentados com cacau em pó, mostrou que sua utilização desse composto inibe a expressão de estresse no retículo endoplasmático, causando melhoras em situações de hiperlipidemia e aterosclerose. Esse fato pode ser explicado especialmente pela rica concentração em flavonoides e compostos fenólicos (GUAN et al., 2016).

Os mecanismos pelo qual o cacau reduz a PA não são totalmente explorados, porém existem estudos que comprovam que há a liberação de óxido nítrico (NO) após ingestão de produtos provindos do cacau. Também pode-se levar em conta a inibição da enzima conversora de angiotensina pelos flavonóis ou pela teobromina, o que pode contribuir para esse efeito (DESCH et al., 2010; MAGRONE et al., 2017).

A enzima conversora de angiotensina (ECA) é uma das responsáveis pelo aumento da PA, pois faz a conversão da angiotensina I e II contribuindo para a vasoconstrição. A presença de fatores que inibem esse mecanismo faz com que os produtos com grande concentração de cacau tragam benefícios como os de um fármaco utilizado para amenizar os efeitos da hipertensão arterial sistêmica (HAS) (GIGLIO et al., 2018).

Duarte et al. (2016) demonstra resultados imediatos na PA e variabilidade da frequência cardíaca após o consumo de uma única dose de chocolate amargo. Os indivíduos submetidos a ingerir a dose de chocolate [10g] 70\% cacau obtiveram uma diminuição da pressão arterial, assim como um aumento na variabilidade da frequência cardíaca, pouco tempo após ingestão.

\subsection{Efeitos nas dislipidemias e colesterol}

Os flavonoides relacionados ao cacau apresentam função antiaterosclerótica 
porque diminuem a oxidação do colesterol-LDL, principalmente pela via antioxidante. Quando há maior eliminação de radicais livres no plasma a oxidação de lipídios é atenuada, decrescendo, assim, a adesão destes nos vasos sanguíneos. Pode-se também observar o aumento nos níveis do colesterol-HDL no plasma sanguíneo (MAGRONE et al., 2017) (BADRIE et al., 2014).

Segundo Santos et al. (2018), a ingestão de cacau em pó e seus derivados por até três semanas, elevou em média os níveis de colesterol-HDL em 1,8 mg/dL. A hipótese por trás disto é que os compostos fenólicos aumentam a síntese de apolipoproteína A-1 (ApoA1) no fígado e intestinos. Sendo que está é uma das precursoras do colesterol-HDL.

\subsection{Efeitos cutâneos}

Além de ser um produto versátil para o consumo, há estudos evidenciando o uso do cacau em produtos cosméticos, como cremes corporais de uso tópico, onde através de seus diversos compostos antioxidantes vem demonstrando efeitos no combate ao envelhecimento cutâneo, além de grande capacidade de hidratação (SILVA et al., 2013).

Em estudo onde aplicou-se o extrato alcoólico do cacau em ratos submetidos à exposição ultravioleta (UV) em um período de 15 semanas, obteve-se efeito benéfico em relação ao envelhecimento. Essas implicações podem estar relacionadas à ação dos compostos fenólicos e xantínicos do cacau (SILVA et al., 2013).

Kang (2016) mostrou diminuição de sintomas causados por dermatite atópica (DA) em ratos. Os animais expostos ao extrato de cacau apresentaram maior hidratação das áreas afetadas pela DA, menor número de mastócitos, eosinófilos, citocinas e $\lg \mathrm{E}$, normalmente presentes em inflamações, e atenuação de sintomas provindos da doença. Isso devido ao seu alto teor de polifenóis, os quais regularam a produção e secreção de substâncias pró-inflamatórias.

\section{CONCLUSÃO}

A partir dos resultados obtidos observou-se que o cacau causa inúmeros benefícios funcionais à saúde dos consumidores. Esses benefícios foram comprovados no sistema cardiovascular, em dislipidemias e na saúde dérmica. Para resultados eficazes e a longo prazo é necessário introduzir o cacau e suas fontes em uma dieta balanceada.

É necessário realizar o consumo de fontes saudáveis, sem muita adição de 
açúcares e conservantes, sempre priorizando os produtos com menor processamento possível, como as polpas de cacau, o cacau em pó e os óleos extraídos do cacau. Isso porque produtos com baixa concentração de cacau e maior concentração de açúcares e outros aditivos, além de não trazer os benefícios esperados, podem levar a um aumento de peso indesejado.

\section{REFERÊNCIAS}

BADRIE, N. et al. Cocoa Agronomy, Quality, Nutritional, and Health Aspects. Critical Reviews In Food Science And Nutrition, [s.I.], v. 55, n. 5, p.620-659, 11 nov. 2014.

BASTOS, D.H. M.; ROGERO, M.M.; AREAS, J.A.G. Mecanismos de ação de compostos bioativos dos alimentos no contexto de processos inflamatórios relacionados à obesidade. Arquivos Brasileiros de Endocrinologia \& Metabologia, [s.l.], v. 53, n. 5, p.646-656, jul. 2009.

COLOMBO, A.M.J.; VALENTE FILHO, J.M.; MOREIRA, D.M. Effects of Chocolate in the Endothelial Function of Patients with Acute Coronary Syndrome. International Journal Of Cardiovascular Sciences, [s.I.], v. 28, n. 2, p.89-94, 2015.

CUÉLlAR, O.; GUERRERO, G. Actividad antibacteriana de la cáscara de cacao, Theobroma cacao L. Revista Mvz Córdoba, [s.I.], v. 17, n. 3, p.3176-3183, 8 set. 2012.

DESCH, S. et al. Effect of Cocoa Products on Blood Pressure: Systematic Review and MetaAnalysis. American Journal Of Hypertension, [s.I.], v. 23, n. 1, p.97-103, 1 jan. 2010.

DUARTE, A. A. M. et al. A single dose of dark chocolate increases parasympathetic modulation and heart rate variability in healthy subjects. Revista de Nutrição, [s.I.], v. 29, n. 6, p.765-773, dez. 2016.

EFRAIM, P.; ALVES, A.B.; JARDIM, D.C.P. Revisão: Polifenóis em cacau e derivados. Brazilian Journal Of Food Technology, [s.I.], v. 14, n. 03, p.181-201, 14 set. 2011. 
FILDEMAN, A.; LANGE, T. N. Incongruências no regulamento técnico para chocolate e produtos de cacau que interferem na qualidade do chocolate brasileiro e na saúde do connsumidor. Higiene Alimentar, Salvador, v. 32, n. 267, p.23-27, fev. 2018.

FONSECA-SANTOS, B. et al. Organic cocoa extract -loaded surfactant-based systems intended to skin bioadhesion. Brazilian Journal Of Pharmaceutical Sciences, [s.I.], v. 53, n. 3, p.1-13, 26 out. 2017.

GAMMONE, M. A. et al. Impact of chocolate on the cardiovascular health. Frontiers In Bioscience, [s.I.], v. 23, n. 3, p.852-864, 2018.

GENOVESE, M. I.; LANNES, S. C. S. Comparison of total phenolic content and antiradical capacity of powders and. Ciência e Tecnologia de Alimentos, [s.I.], v. 29, n. 4, p.810-814, dez. 2009.

GIGLIO, R. V. et al. Polyphenols: Potential Use in the Prevention and Treatment of Cardiovascular Diseases. Current Pharmaceutical Design, [s.I.], v. 24, n. 2, p.239-258, 5 abr. 2018.

GIRALDO, M. et al. Ensayo clínico aleatorizado y controlado del efecto del consumo de cacao en pacientes con resistencia a la insulina. Acta Med Colomb, [s.l], v. 42, n. 2, p.90-96. 2017.

GUAN, H. et al. Dietary Cocoa Powder Improves Hyperlipidemia and Reduces Atherosclerosis in apoE Deficient Mice through the Inhibition of Hepatic Endoplasmic Reticulum Stress. Mediators Of Inflammation, [s.I.], v. 2016, p.1-11, 2016.

KANG, $\mathrm{H}$. et al. Theobroma cacao extract attenuates the development of Dermatophagoides farinae-induced atopic dermatitis-like symptoms in NC/Nga mice. Food Chemistry, [s.I.], v. 216, p.19-26, fev. 2017.

KHAN, N. et al. Cocoa Polyphenols and Inflammatory Markers of Cardiovascular Disease. Nutrients, [s.I.], v. 6, n. 2, p.844-880, 21 fev. 2014. 
LOFFREDO, L. et al. Effects of dark chocolate on endothelial function in patients with nonalcoholic steatohepatitis. Nutrition, Metabolism And Cardiovascular Diseases, [s.I.], v. 28, n. 2, p.143-149, fev. 2018.

MAGRONE, T.; RUSSO, M. A.; JIRILLO, E. Cocoa and Dark Chocolate Polyphenols: From Biology to Clinical Applications. Frontiers In Immunology, [s.I.], v. 8, p.1-13, 9 jun. 2017.

MCDOUGALL, G.J. Phenolic-enriched foods: sources and processing for enhanced health benefits. Proceedings Of The Nutrition Society, [s.I.], v. 76, n. 02, p.163-171, 2 nov. 2016.

MEDEIROS, M.L.; LANNES, S.C.S. Propriedades físicas de substitutos do cacau. Ciência e Tecnologia de Alimentos, [s.I.], v. 30, p.243-253, maio 2010.

MUNGUIA, L. et al. Beneficial effects of a flavanol-enriched cacao beverage on anthropometric and cardiometabolic risk profile in overweight subjects. Rev. Mex. Cardiol, [s.I], v. 26, n. 2, p.78-86, 2015.

NOGUEIRA, B.L. Processamento do cacau: avaliação do teor nutricional do chocolate e dos outros derivados do cacau. 2015. 47 f. TCC (Graduação) - Curso de Engenharia Bioquímica, Universidade de São Paulo, Lorena, 2015.

RIBEIRO, G.; SANTOS, O. Recompensa alimentar: mecanismos envolvidos e implicações para a obesidade. Revista Portuguesa de Endocrinologia, Diabetes e Metabolismo, [s.I.], v. 8, n. 2, p.82-88, jul. 2013.

VICENTIM, A.; MARCELLINO, M.C.L. Efeito do pó de cacau (Theobroma Cacao) e seus princípios ativos na pressão arterial de portadores do Diabetes Mellitus Tipo II. Salusvita, v. 31, n. 1, p. 29-40, 2012. 